\title{
A Atuação da Comissão Institucional de Heteroidentificação da UNIVASF na Chamada Regular do SISU 2021 para Cursos de Graduação Presenciais
}

\author{
Leilane Diena Souza da Silva ${ }^{1}$; Marcelo Henrique Pereira dos Santos ${ }^{2}$
}

\begin{abstract}
Resumo: Este artigo visa analisar a atuação da Comissão Institucional de Heteroidentificação da Universidade Federal do Vale do São Francisco - Univasf durante a Chamada Regular do Sistema de Seleção Unificada (Sisu) 2021, com o objetivo de discutir a questão racial no Brasil a partir da ideia de raça e identidade racial e efetivação da implementação da Lei 12.711/2012 que prevê o ingresso de negros na educação superior brasileira. A Univasf oferta 30 cursos de graduação presenciais, com um total de 1610 vagas, em sete Campi nos estados da Bahia, Pernambuco e Piauí, tendo adotado a Política de Cotas estabelecida na Lei $12.711 / 2021$, reservando $50 \%$ das vagas para candidatos oriundos de escolas públicas e/ou autodeclarados. Dessas vagas, 568 (quinhentas e sessenta e oito) são reservadas para candidatos autodeclarados. Da análise dos dados divulgados no site da Univasf sobre as aferições realizadas durante a Chamada Regular do Sisu 2021, que aconteceram no período de 17 de abril a 17 de junho de 2021, 317 (trezentos e dezessete) candidatos estavam aptos a participar do procedimento de heteroidentificação. A partir dos dados coletados, o presente artigo discute a importância da Comissão Institucional de Heteroidentificação para o fortalecimento da Política Pública de Cotas. A pesquisa foi realiza através da análise de documentos públicos encontrados nas páginas oficiais da Univasf e de normativas internas e nacionais sobre o tema.
\end{abstract}

Palavras-chave: Comissão Institucional de Heteroidentificação; Política de Cotas Raciais; Sisu 2021.

\section{The Performing of the Institutional Committee for Heteroidentification of Univasf in the Regular Call of SISU 2021 for on-site graduation courses}

\begin{abstract}
This article aims to analyze the performance of the Institutional Commission for Heteroidentification of Federal University of Vale do São Francisco - Univasf during the Regular Call of Unified Selection System (Sisu) 2021, in order to discuss the racial issue in Brazil from the idea of race and racial identity and the implementation of Law 12,711/2012 that provides for the entry of blacks in Brazilian higher education. Univasf offers 30 on-site graduate courses, with a total of 1610 vacancies, in seven campuses in the states of Bahia, Pernambuco and Piauí, having adopted the Quota Policy established in Law 12,711/2021, reserving 50\% of the vacancies for candidates from public schools and/or self-declared. Of these vacancies, 568 (five hundred and sixtyeight) are reserved for self-declared candidates. From the analysis of the data published on the Univasf website about the measurements carried out during the Sisu 2021 Regular Call, which took place from April 17 to June 17, 2021, 317 (three hundred and seventeen) candidates were able to participate in the procedure of heteroidentification. Based on the collected data, this article discusses the importance of the Institutional Commission for Heteroidentification for the strengthening of the Public Quota Policy. The research was carried out through the analysis of public documents found on the official pages of Univasf and internal and national regulations on the subject.
\end{abstract}

Keywords: Institutional Commission for Heteroidentification; Racial Quota Policy; Sisu 2021.

\footnotetext{
${ }^{1}$ Bacharel em Direito pela Universidade do Estado da Bahia - UNEB e discente do Mestrado Profissional em Administração Pública - Profiap-UNIVASF.

2 Doutor em Ciência Política pela Pontifícia Universidade Católica de São Paulo - PUC-SP e professor do Colegiado de Ciências Sociais da Universidade Federal do Vale do São Francisco - UNIVASF e do Mestrado Profissional em Administração Pública - Profiap-UNIVASF.

*Autor correspondente: marcelo.henrique@univasf.edu.br
} 


\section{Introdução}

O presente trabalho busca abordar a Política Pública de Cotas nas Universidades Federais, através da análise da implementação da Comissão Institucional de Heteroidentificação da Univasf, a partir da sua atuação durante a Chamada Regular do Sistema de Seleção Unificada (Sisu) 2021.

A alternativa de adotar o sistema de cotas tem como objetivo minimizar as desigualdades da sociedade. Isso se deve ao fato de que certos grupos, por conta do processo histórico vivenciado, vêm sendo injustiçados e acabam tendo maiores dificuldades, por motivos de discriminações, para se integrarem à sociedade ou se inserirem no mercado de trabalho.

A Política de Cotas funciona como uma estratégia para a redução dessas desigualdades, agindo como um instrumento mais célere na inclusão social de grupos que estão à "margem" da sociedade - entre eles, negros, indígenas, pessoas com deficiência - e, visando com isso a redução dos obstáculos que os marginalizam na sociedade.

Conforme se observa, as cotas, dentre outras razões, têm como base a questão racial dos candidatos. Sendo o Brasil um país que tem a desigualdade social intimamente ligada ao sentido de cor/raça, se fez necessária a criação de mecanismo para que houvesse inclusão de grande parte da população marginalizada em políticas públicas capazes de realizar mudança no estrato social.

O Brasil foi formado através do trabalho negro decorrente da escravidão. Mesmo após a abolição da escravatura em 1888, à população negra não foi garantida condições de sobrevivência digna, passando esse grupo a constituir parte marginalizada e vulnerável da sociedade brasileira.

A aprovação da Lei 12.711/2012, a chamada Lei de Cotas, garantiu a reserva de vagas para candidatos negros (pretos e pardos) nas Universidades Federais do Brasil. A referida lei apresenta a técnica de autodeclaração como critério de confirmação da cor/raça do candidato. Contudo, em razão das declarações falsas e das denúncias que passaram a ocorrer após a instituição da Política de Cotas, foi necessário a criação das Comissões de Heteroidentificação que funcionam como mecanismo para complementar a autodeclaração do candidato.

A Portaria Normativa $n^{0}$ 04/2018 do Ministério do Planejamento, Orçamento e Gestão, por sua vez, prevê como as comissões devem ser formadas, de que maneira devem atuar e como devem ser implementadas nas instituições, inicialmente tratando no tocante aos concursos 
públicos e posteriormente sendo utilizada como fonte para a implementação das comissões na Universidades Federais.

Assim, o presente artigo busca discutir a atuação da Comissão Institucional de Heteroidentificação da UNIVASF na Chamada Regular do Sisu 2021, trazendo o debate da questão racial no país e a implementação da Lei 12.711/2012.

\title{
Raça e Identidade Racial
}

No século XVI, o termo raça era utilizado em sentido literário, significando um grupo ou categoria de pessoas conectadas por uma origem comum. Já no século XIX, o conceito de raça aparece nas teorias biológicas.

Neste sentido, afirma Machado (2020),

\begin{abstract}
No século XVIII, entre outras categorizações realizadas, passou-se a considerar a cor da pele um critério importante na classificação dos seres humanos, para a identificação das raças. A partir desse período a espécie humana foi dividida em três raças: branca, amarela e negra. O século XIX acrescentou à característica da cor da pele, critérios morfológicos como, por exemplo, o formato do nariz dos lábios do queixo e do crânio (MACHADO, 2020, p. 22).
\end{abstract}

$\mathrm{Na}$ atualidade, o conceito de raça congrega um conteúdo político-ideológico, sendo importante para a exposição das relações de poder e dominação decorrentes do período colonial e escravagista. Apesar de biologicamente raça não existir, a categoria segue presente nas representações e nos imaginários coletivos. Bem como, por razões históricas e políticas, o quesito racial tem determinado o acesso às condições de cidadania e bem-estar social. Vale ressaltar, também, que ao se utilizar o termo raça e ao se identificar as pessoas como negras ou brancas, sabe-se que há dentro dessas categorias grande pluralismo histórico e cultural. (MACHADO, 2020).

O pensamento social brasileiro foi fortemente influenciado pelas doutrinas do racismo científico que deram origem à ideia de raça hierarquizada. Após a abolição da escravidão em 1888, uma das maiores preocupações de intelectuais e políticos do nosso país era que a raça do Brasil fosse melhorada, surgindo a tese do branqueamento. Essa formulação inicialmente científica e, em seguida, adaptada para a política, previa que, na mistura de raças prevalecia o componente genético branco e se essa mistura ocorresse por muitas gerações, o resultado seria ter uma população embranquecida, em que as ancestralidades africanas e indígenas seriam neutralizadas e superadas (MACHADO, 2020). 
O começo do século XX no Brasil foi marcado por ações para o incentivo ao branqueamento, favorecendo a imigração europeia, a proibição da imigração africana e a não concessão de visto para negros norte-americanos. No mesmo período, houve tratamento diferenciado aos europeus com a concessão de terras, capacitação profissional e empregos. $\mathrm{Na}$ realidade, o Brasil ofereceu as condições mínimas necessárias para que essa população europeia e branca se estabelecesse socialmente, em contrapartida, ao povo negro, foi ofertada escravidão por séculos e mesmo após a abolição da escravatura, os negros foram renegados à própria sorte sem nenhum mecanismo de inclusão social.

Apenas em 1930, o Governo Federal adotou políticas para restringir a imigração no país, com a restrição de empregos na indústria e no comércio para estrangeiros, uma vez que a chegada desses imigrantes europeus aumentou a competitividade por trabalho. Com isso, houve o fracasso do projeto de branqueamento do Brasil, e se fez imperiosa a busca por alternativas de desenvolvimento para o país e de formação da identidade nacional.

Com o surgimento do novo século, a legislação brasileira passou a incorporar a questão social de modo mais amplo para combater as desigualdades estruturais, porém é forçoso reconhecer como tais ações ainda estão distantes do necessário. A abordagem das desigualdades educacionais em decorrência das questões de raça começou a ser pautada academicamente nas ciências sociais apenas na década de 1990.

No ano de 2003, foi criada a Política Nacional de Promoção da Igualdade Racial, bem como ocorreu a promulgação da Lei $n^{0}$ 10639/2002 que incluiu no currículo oficial da rede de ensino a obrigatoriedade da temática "História e Cultura Afro-Brasileira". Foi também naquele ano que houve a criação da Secretaria Especial de Políticas de Promoção da Igualdade Racial.

Em 2004, foi criado pelo Governo Federal o Programa Universidade para Todos (PROUNI), o qual ampliou o acesso ao ensino superior, buscando reduzir desigualdades de oportunidades que perduram na sociedade brasileira. Esse programa foi um dos balizadores da Política de Cotas para as Universidades Federais, uma vez que o seu modelo de concessão de bolsas se assemelha muito às vagas reservadas na Lei de Cotas.

Inicia-se assim, de modo gradual e crescente, a implementação de ações afirmativas nas Universidades Brasileiras no âmbito federal e, em 2012 é aprovada a Lei 12.711/2012, a chamada Lei de Cotas. 


\section{A Lei 12.711/12 e a Política de Cotas para Negros}

Diante do racismo e das desigualdades sociais e raciais, se observou a necessidade de implementação de políticas capazes de diminuir as dificuldades enfrentadas pelo povo negro e os socialmente marginalizados, em função das vulnerabilidades históricas, sociais e econômicas vivenciadas. Uma dessas políticas é a possibilidade de ingresso em Universidades Públicas através das cotas raciais, conforme ilustram os estudos de Marques (2010), Gomes (2011), Santos (2008), Heringer (2009), Feres Junior et al. (2013), entre outros.

A alternativa de adotar o sistema de cotas tem como objetivo reduzir as desigualdades na sociedade. A política de reserva de vagas atua como uma maneira de reduzir as desigualdades sociais, econômicas e raciais, possibilitando uma forma mais rápida de inclusão social de grupos que estão à margem da sociedade, entre eles, negros, indígenas, pessoas com deficiência, buscando assim remover as barreiras que os excluem.

A Universidade Estadual do Rio de Janeiro (UERJ) foi a primeira Universidade Pública, no ano de 2001, a adotar a reserva de vagas. As cotas implementadas tinham caráter social e racial, sendo designadas a estudantes egressos da escola pública, negros e a pessoas com deficiência. A situação, segundo Santos (2012), gerou muita polêmica e muitos debates foram realizados naquele período entre a comunidade universitária e também externa. Além disso, motivou duas ações de inconstitucionalidade contra as cotas, propostas ao Tribunal de Justiça do Rio de Janeiro e, tendo em seguida, ganhado espaço nacional com o julgamento realizado pelo Superior Tribunal Federal, o qual só ocorreu em 2012 e declarou a constitucionalidade das cotas.

No nível federal, a Universidade de Brasília foi a primeira Universidade Pública a instituir a Política de Cotas, em 2004, implementando cotas raciais para negros e indígenas e fortalecendo o sistema de ensino público local. A UNB foi a pioneira, se tornando referência para outras Universidades Federais do país.

Nos últimos anos, os debates se intensificaram e diversas experiências se concretizaram, sendo que em 29 de agosto de 2012 foi sancionada pela Presidente Dilma Rousseff a Lei $\mathrm{N}^{\mathrm{o}}$ 12.711/12, mais conhecida como "Lei das Cotas" que dispõe sobre o ingresso nas Universidades Federais e nos Institutos Federais de Ensino Técnico de Nível Médio.

A Lei n 12.711, a chamada "Lei de Cotas", dispõe em seu art. $1^{\circ}$ que:

As instituições federais de educação superior vinculadas ao Ministério da Educação reservarão, em cada concurso seletivo para ingresso nos cursos de graduação, por 
curso e turno, no mínimo 50\% (cinquenta por cento) de suas vagas para estudantes que tenham cursado integralmente o ensino médio em escolas públicas. (BRASIL, 2012).

No artigo $4^{\circ}$ da referida Lei consta que:

As instituições federais de ensino técnico de nível médio reservarão, em cada concurso seletivo para ingresso em cada curso, por turno, no mínimo 50\% (cinquenta por cento) de suas vagas para estudantes que cursaram integralmente o ensino fundamental em escolas públicas (BRASIL, 2012).

O parágrafo único do artigo $1^{\circ}$ e do artigo $4^{\circ}$ institui que " $50 \%$ (cinquenta por cento) dessas vagas deverão ser reservados aos estudantes oriundos de famílias com renda igual ou inferior a 1,5 salário-mínimo (um salário-mínimo e meio) per capita”. A lei prevê ainda, nos $\operatorname{artigos} 3^{\circ}$ e $5^{\circ}$, que as vagas reservadas a estudantes oriundos de escolas públicas:

[...] serão preenchidas, por curso e turno, por autodeclarados pretos, pardos e indígenas, em proporção no mínimo igual à de pretos, pardos e indígenas na população da unidade da Federação onde está instalada a instituição, segundo o último censo do Instituto Brasileiro de Geografia e Estatística (BRASIL, 2012).

A Lei $\mathrm{n}^{\circ}$ 12.711/2012 fixa o percentual de vagas reservadas para aqueles oriundos de escolas públicas, estabelecendo critérios socioeconômicos e considerando, ainda, o perfil de cor das populações dos estados em que as instituições se localizam. Com isso, a quantidade de vagas oferecidas ao grupo composto por pretos, pardos e indígenas é estabelecida de acordo com as características demográficas de cada estado, sendo este um dos aspectos mais importantes da nova lei.

A Lei 12.711/2012 sinalizou como principal critério de candidatura para cotas a origem escolar (egresso de escola pública), submetido a este o critério de renda e o étnico. Ficou estabelecido também que as instituições teriam o prazo máximo de 4 (quatro) anos, a partir da publicação da Lei 12.711/2012, para o cumprimento integral do percentual de reserva de vagas, sendo necessário implementar no mínimo 25\% (vinte e cinco por cento) a cada ano. Além disso, no prazo de dez anos a contar da publicação da Lei, será promovida a revisão do programa especial para o acesso às instituições de educação superior de estudantes pretos, pardos e indígenas e de pessoas com deficiência, bem como daqueles que tenham cursado integralmente o ensino médio em escolas públicas, o que ocorrerá, portanto, em 2022.

A aprovação da Lei 12.711/2012 estabelecendo um percentual de reserva de vagas para o acesso ao ensino superior regulamentou e uniformizou uma situação que ocorria na maioria 
das instituições federais de ensino superior, tornando-se um marco para a política de ação afirmativa na modalidade de cotas para a educação superior.

\title{
Da Necessidade do Procedimento de Heteroidentificação e Criação das Comissões de Heteroidentificação
}

Com o surgimento das cotas raciais, diferentes critérios foram adotados pelas Universidades Públicas para a identificação racial dos candidatos. A percepção dos processos sociais de formação identitária é decisiva para a reflexão sobre o desenho e os critérios adotados na concretização das ações afirmativas (RIOS, 2018)

A Lei n.12.711/2012 prevê o critério de autodeclaração para que os candidatos possam concorrer às vagas. Contudo, apesar de ser a autodeclaração um ponto de partida, se fez necessária a adoção de outras técnicas como forma de complementar a autodeclaração do candidato.

A autodeclaração racial é trazida no bojo do Estatuto da Igualdade Racial, o qual traz como definição da população negra "o conjunto de pessoas que se autodeclaram pretas e pardas, conforme o quesito cor ou raça usado pelo IBGE, ou que adotam autodefinição análoga" (BRASIL, 2010).

Para fins de políticas afirmativas, segundo ressalta Fagundes (2020)

\begin{abstract}
A pergunta "Qual a sua cor/raça?" se refere à visão do indivíduo sobre como é socialmente percebido. Isso porque, por sua finalidade, as ações afirmativas estão conectadas ao aspecto social do pertencimento racial (identidade heteroatribuída), e não ao individual (autodefinição), porque é essa dimensão que permite mitigar os efeitos do preconceito racial. Perguntas sobre níveis de classificação racial diferentes podem retornar respostas diferentes. Por isso a autodeclaração racial pode assumir um caráter absoluto, quando relacionada ao direito subjetivo do declarante de informar seu pertencimento racial, como sente e percebe a si próprio. Por outro lado, tem necessariamente uma dimensão relativa quando está relacionada à concessão de um direito material, como no caso das cotas raciais (FAGUNDES, 2020, p.30)
\end{abstract}

A questão de se declarar negro, por si só, não torna o indivíduo sujeito à discriminação racial e é justamente a existência dessa discriminação que se visa mitigar por meio das cotas. Para fins de políticas públicas, como as cotas raciais, o pertencimento racial indagado é o social, e não o individual. Não se pretende negar ou reduzir a importância da autodefinição racial, mas o que justifica o estabelecimento de medidas afirmativas é o tratamento desigual estabelecido por uma sociedade que hierarquiza a classificação racial (FAGUNDES, 2020, p.32).

Para Ballentine (apud Rios, 2018) 
A heteroidentificação é o método de identificação que utiliza a avaliação de um terceiro para a identificação étnico-racial de um indivíduo. Ela pode se valer de diversos critérios, tais como elementos biológicos, como o fenótipo e a cor da pele; ancestralidade, ou até mesmo servir-se do construcionismo identitário. (BALLENTINE apud RIOS, 2018, p.149)

Em relação à Lei de Cotas nas Universidades Federais, a autodeclaração racial é requisito essencial e primário para que alguém se habilite a concorrer pelas cotas, mas se mostrou insuficiente, nesse contexto, como requisito único, por deixar a política especialmente vulnerável ao desvio de sua finalidade.

De acordo com Jesus (2008 apud Fagundes,2020), tem-se que:

A compreensão expressa por Daniela Ikawa, e acolhida pelo Ministro Lewandowski, reconhece, portanto, que a definição do pertencimento racial dos indivíduos na sociedade brasileira não se dá de modo isolado, baseada apenas na definição "autônoma" dos sujeitos. Trata-se, na realidade, de uma negociação que se dá em diferentes espaços socializadores e que passa, necessariamente, pela definição que os outros fazem do pertencimento racial de cada um. Deste modo, ao mesmo tempo em que reconhece a importância da autodeclaração como princípio basilar do modo como os sujeitos se definem, o Ministro Lewandowski não desconsidera o importante lugar da classificação externa na definição da identidade dos indivíduos (JESUS, 2018, p. 131)

Mesmo a Lei de Cotas não prevendo especificamente um mecanismo de verificação da autodeclaração racial, ela traz a previsão de punição da falsa declaração, já indicando que, mesmo havendo a presunção de veracidade da autodeclaração racial, esta não é absoluta. (FAGUNDES, 2020, p.33)

Marques e Brito (2016) afirmam que:

[...] a existência da banca avaliadora constitui-se em mecanismo que coíbe a interpretação errônea ou fraudulenta de pertencimento étnico-racial e configurase num espaço de diálogo com os candidatos, no sentido de apontar que os conflitos apresentados pelos mesmos para se afirmarem como pretos ou pardos, é resultante de um processo de negação e de invisibilidade da população negra no Brasil.

O procedimento de Heteroidentificação foi inicialmente regulamentado pelo Ministério do Planejamento, Orçamento e Gestão por meio da Orientação Normativa $n^{\circ}$ 03, publicada em agosto de 2016. Essa norma tornou obrigatória a verificação da autodeclaração racial para cotas no tocante aos concursos públicos federais para ingresso dos servidores, cabendo ao edital de abertura definir os procedimentos que deveriam ser seguidos. Determinou-se que a aferição seria feita por uma comissão, a partir do fenótipo do candidato.

Essa Orientação foi revogada pela Portaria Normativa ${ }^{\circ}$ 04/2018, expedida pelo mesmo órgão, regulamentando o procedimento de forma mais detalhada, uma vez que foi elaborada 
por um grupo de trabalho instituído com essa finalidade específica. Esse documento legal, elaborado numa perspectiva de manutenção da finalidade das cotas raciais, propõe um modo apto a prevenir fraudes.

A Portaria Normativa ${ }^{\circ}$ 04/2018 deixa explícita desde sua epígrafe que o procedimento de aferição é complementar à autodeclaração. Ou seja, a autodeclaração é o quesito principal e a heteroidentificação seu acessório.

De acordo com Nunes a

\begin{abstract}
Comissão de verificação é uma responsabilidade de gestão de ações afirmativas não [só] pelo que se negligenciou a partir da 12711/12 e 12990/14, mas pela emergência de um outro patamar de relações sociais em que o corpo possa ser desracializado pelo fenótipo tido como desvirtuoso em relação à virtude branca. As comissões não fazem um julgamento de corpos, mas instauram um processo político de acolhimento e recepção aos corpos esquecidos, interditados e normatizados pelo racismo (NUNES, 2018, p. 28).
\end{abstract}

Apesar de inicialmente ser uma Portaria que regulamenta a Lei de vagas reservadas para concurso público de servidores, os critérios determinados naquela normativa passaram a ser norteadores das Comissões de Heteroidentificação das Universidades Federais, inclusive adotados pela UNIVASF em seus instrumentos normativos internos.

\title{
Implementação da Comissão Institucional de Heteroidentificação da Univasf
}

Com o advento da Lei 12.711/2012, a Lei de Cotas, as Universidades Federais passaram a ter que reservar 50\% das suas vagas para os alunos de escola pública e dentre esses alunos um percentual deveria ser reservado para os candidatos negros (pardos e pretos). A Univasf, a partir de 2013, adotou essa política em seus vestibulares, no entanto, para concorrer às vagas reservadas aos candidatos negros bastava apenas uma autodeclaração.

Até então, apenas os candidatos que eram denunciados por não serem pardos ou pretos é que tinham sua autodeclaração verificada pela IES em Comissão de Verificação instituída apenas para esse fim. Isso mudou a partir do processo seletivo SISU 2020. Em 2019, a Univasf por meio da IN 07/2019 criou a Comissão Institucional de Heteroidentificação que passou a ser responsável pela aferição dos candidatos que concorrem às vagas reservadas para negros. Naquele mesmo ano, a UNIVASF por meio da Resolução nº 24/2019 no CONUNI instituiu a reserva de vagas para candidatos negros nos cursos de pós-graduação. 
No ano de 2020, a Comissão constituída por cerca de 25 servidores (docentes e técnicos) passou a ser responsável pelo processo de heteroidenticação de todos os candidatos autodeclarados negros nos processos seletivos de graduação presencial da Univasf. Inicialmente, as atividades ocorreram de forma presencial referente ao Edital 01/2020 da PROEN, sendo realizadas as aferições nos meses de fevereiro e março daquele ano, inclusive em todos os Campi da instituição. Para isso, foram deslocadas equipes de servidores para os Campi de Senhor do Bonfim, Salgueiro e Paulo Afonso. Nos demais Campi as equipes foram formadas por servidores lotados no respectivo Campus. No entanto, com a chegada da Pandemia do Covid-19 e a suspensão das atividades de forma presencial, as aferições passaram a ocorrer de forma remota, de acordo com IN 01/2021 GR/ UNIVASF.

Em 12 de abril de 2021, foi publicada a Instrução Normativa ${ }^{\circ}$ 02/2021 pelo Gabinete da Reitoria, que revogou a IN 07/2019 GR/UNIVASF e que instituiu a Comissão Institucional de Heteroidentificação, regulamentando procedimento de heteroidentificação da Univasf para o ingresso nas graduações, pós-graduação, concursos e processos seletivos.

A principal mudança instituída pela IN 02/2021 GR/UNIVASF no tocante a IN 07/2019 GR/UNIVASF foi a ampliação do número de membros das bancas de análise e o número de votos favoráveis para a confirmação da autodeclaração do candidato. Até então as aferições eram realizadas apenas com três membros e o candidato era considerado compatível com apenas um voto a favor. O que passou a não acontecer com o advento da IN 02/2021 GR/UNIVASF:

\footnotetext{
Art. $6^{\circ}$. O procedimento de heteroidentificação será realizado por banca formada por 5 (cinco) membros e 2 (dois) suplentes dentre os servidores que compõem a Comissão Institucional de Heteroidentificação da Univasf (CIHU)

Art. $8^{\circ}$. A decisão da Comissão Institucional de Heteroidentificação da Univasf (CIHU), pelo DEFERIMENTO ou INDEFERIMENTO da posse ou matrícula, será tomada pela banca de aferição, que deliberará pela maioria simples dos seus membros, sob forma de parecer motivado, considerando como critério único e exclusivo o fenótipo no processo de análise e validação, excluídas as considerações sobre a ascendência, fotografias ou documentos pretéritos. (UNIVASF, 2021)
}

Assim, ficou estabelecido que as bancas de heteroidentificação serão compostas por cinco membros e não três como previa a norma anterior e que para a confirmação da autodeclaração é preciso a maioria simples dos votos dos membros da banca. Além disso, a Banca Recursal será composta por três membros distintos da primeira banca e o parecer favorável ao recurso será pelo voto da maioria simples. 
A IN 02/2021 do GR/UNIVASF também resguarda que apenas o fenótipo do candidato será analisado, não devendo ser considerados registros ou documentos pretéritos, conforme se observa da leitura dos $\S 1^{\circ}$ a $\S 3^{\circ}$ do art. $8^{\circ}$ :

\begin{abstract}
$\S 1^{\circ}$ Entende-se por fenótipo o conjunto de características físicas do indivíduo, predominantemente, a cor da pele, a textura do cabelo e os aspectos faciais, que, combinados ou não, permitirão validar ou invalidar a autodeclaração.

$\S 2^{\circ}$ As características fenotípicas descritas no parágrafo anterior são as que possibilitam, nas relações sociais, o reconhecimento do indivíduo como preto ou pardo.

$\S 3^{\circ}$ Não serão considerados, para fins do caput, quaisquer registros ou documentos pretéritos eventualmente apresentados, inclusive imagem e certidões referentes a confirmação em procedimentos de heteroidentificação realizados em concursos públicos federais, estaduais, distritais e municipais.
\end{abstract}

\title{
Conforme problematizado por Livia Vaz:
}

\begin{abstract}
No Brasil, predomina o preconceito racial de marca, de modo que a discriminação é praticada por meio de construções sociais que promovem a exclusão de determinadas pessoas, em razão de suas características fenotípicas - tais como cor da pele, traços faciais e textura dos cabelos -, associadas ao grupo étnico-racial a que pertencem. Assim, o racismo à brasileira afeta os indivíduos em virtude de sua aparência racial - que determina sua potencial vulnerabilidade à discriminação racial, e não de sua ascendência ou composição genética (VAZ, 2018, p.37)
\end{abstract}

Assim, não há que ser levado em consideração pela Comissão de Heteroidentificação documentos, registros ou qualquer outro concurso anterior realizado pelo candidato, sendo analisado tão somente o fenótipo no momento da heteroidentificação.

\section{Atuação da Comissão Institucional de Heteroidentificação da Univasf na chamada regular do Sisu 2021 para cursos de graduação presenciais: análise e resultados}

A Univasf oferta 30 cursos de graduação presenciais, com um total de 1610 vagas, em sete Campi nos estados da Bahia, Pernambuco e Piaú. Desde 2013, a Univasf adotou a Política de Cotas estabelecida na Lei 12.711/2021, reservando 50\% das vagas para candidatos oriundos de escolas públicas e/ou autodeclarados.

A Portaria $\mathrm{n}^{\mathrm{o}}$ 18/2012 do MEC, regulamentou a Lei 12.711/12 e estabeleceu que:

Art. $3^{\circ}$ As instituições federais vinculadas ao Ministério da Educação - MEC que ofertam vagas de educação superior reservarão, em cada concurso seletivo para ingresso nos cursos de graduação, por curso e turno, no mínimo 50\% (cinquenta por cento) de suas vagas para estudantes que tenham cursado integralmente o ensino médio em escolas públicas, inclusive em cursos de educação profissional técnica, observadas as seguintes condições:

[...] 
II - proporção de vagas no mínimo igual à da soma de pretos, pardos e indígenas na população da unidade da Federação do local de oferta de vagas da instituição, segundo o último Censo Demográfico divulgado pelo Instituto Brasileiro de Geografia e Estatística - IBGE, será reservada, por curso e turno, aos autodeclarados pretos, pardos e indígenas.

Em 2016, por meio da Lei n ${ }^{\circ} 13.409$ houve alteração da Lei 12.711/2012 incluindo na reserva de vagas as pessoas com deficiência, observando os mesmos critérios, ou seja, a proporção de presença dessas pessoas na população da unidade da Federação onde está instalada a instituição, segundo o último censo do IBGE (BRASIL, 2016).

Em razão das regras impostas pelo ordenamento jurídico pátrio a Univasf adotou grupos para distribuição das vagas, conforme se observa da leitura do item 4.5 do Edital $n^{\circ}$ 05/2021 PROEN/ UNIVASF

4.5. Com base no disposto neste item (4.), a distribuição das vagas será composta por 9 (nove) grupos, a saber:

a) Grupo L1: vagas reservadas para candidatos com renda familiar bruta per capita igual ou inferior a 1,5 salário mínimo que tenham cursado integralmente o ensino médio em escolas públicas, conforme a alínea "a" do inciso I do item 4.1.;

b) Grupo L2: vagas reservadas para candidatos autodeclarados pretos, pardos ou indígenas, com renda familiar bruta per capita igual ou inferior a 1,5 salário mínimo e que tenham cursado integralmente o ensino médio em escolas públicas, conforme a alínea "a" do inciso I do item 4.1.;

c) Grupo L5: vagas reservadas para candidatos que, independentemente da renda, tenham cursado integralmente o ensino médio em escolas públicas, conforme a alínea "a" do inciso I do item 4.1.;

d) Grupo L6: vagas reservadas para candidatos autodeclarados pretos, pardos ou indígenas que, independentemente da renda, tenham cursado integralmente o ensino médio em escolas públicas, conforme a alínea "a" do inciso I do item 4.1.;

e) Grupo L9: vagas reservadas para candidatos com deficiência que tenham renda familiar bruta per capita igual ou inferior a 1,5 salário mínimo que tenham cursado integralmente o ensino médio em escolas públicas, conforme a alínea "a" do inciso I do item 4.1.;

f) Grupo L10: vagas reservadas para candidatos com deficiência autodeclarados pretos, pardos ou indígenas, que tenham renda familiar bruta per capita igual ou inferior a 1,5 salário mínimo e que tenham cursado integralmente o ensino médio em escolas públicas, conforme a alínea "a" do inciso I do item 4.1.;

g) Grupo L13: vagas reservadas para candidatos com deficiência que, independentemente da renda, tenham cursado integralmente o ensino médio em escolas públicas, conforme a alínea "a" do inciso I do item 4.1.;

h) Grupo L14: vagas reservadas para candidatos com deficiência autodeclarados pretos, pardos ou indígenas que, independentemente da renda, tenham cursado integralmente o ensino médio em escolas públicas, conforme a alínea "a" do inciso I do item 4.1. (UNIVASF, 2021).

Assim, conforme se verifica as vagas reservadas para candidatos autodeclarados negros (pardos e pretos) ou indígenas ficaram estabelecidas nos grupos denominados L2, L6, L10 e L14. Do total de vagas ofertadas em 2021, 568 (quinhentos e sessenta e oito) são reservadas para esses grupos. 
O procedimento de heteroidentificação realizado pela Comissão Institucional, por conta da pandemia, aconteceu por meio do envio de vídeo e preenchimento de formulário, de acordo com o estabelecido na Portaria $\mathrm{n}^{\circ}$ 04/2021 CIHU/CPAA/GR - UNIVASF.

Da análise dos dados divulgados no site da Univasf sobre as aferições realizadas durante a Chamada Regular do Sisu 2020, que aconteceram no período de 17 de abril a 17 de junho de 2021, dos 317 (trezentos e dezessete) candidatos aptos a serem aferidos, após análise dos documentos de pré-matrícula, retirada dos candidatos autodeclarados indígenas e os que não enviaram vídeos, 243 (duzentos e quarenta e três) foram aprovados, o que representa um percentual de $76,65 \%$ de aprovação e 64 (sessenta e quatro) candidatos foram reprovados. Em sede recursal, apenas 31 (trinta um) candidatos apresentaram recurso e desses 21 (vinte um) foram aprovados.

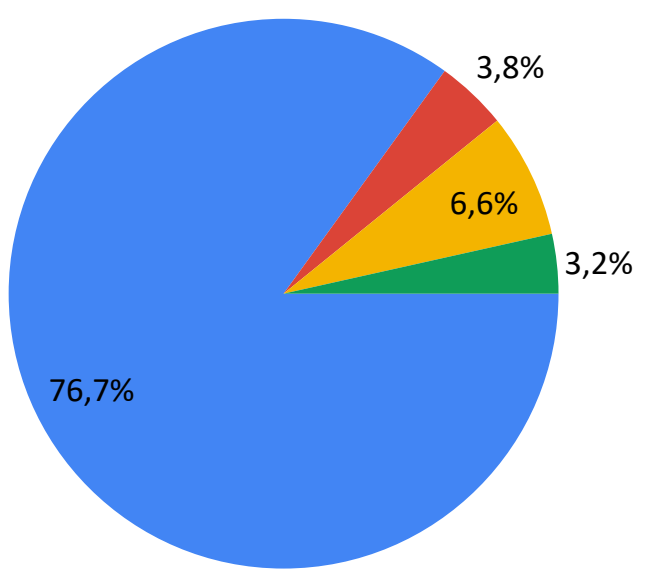

Aprovado $\square$ Indeferido (sem recorrer) $\quad$ Recurso deferido $\quad$ Recurso Indeferido

Figura1: Percentual do número de aprovados, candidatos indeferidos que não apresentaram recurso, candidatos que tiveram o recurso deferido e os que foram incompatíveis pela Banca Recursal.

Assim, conforme se observa na Figura 2, 83\% dos candidatos que passaram pelo processo de heteroidentificação foram aprovados: 


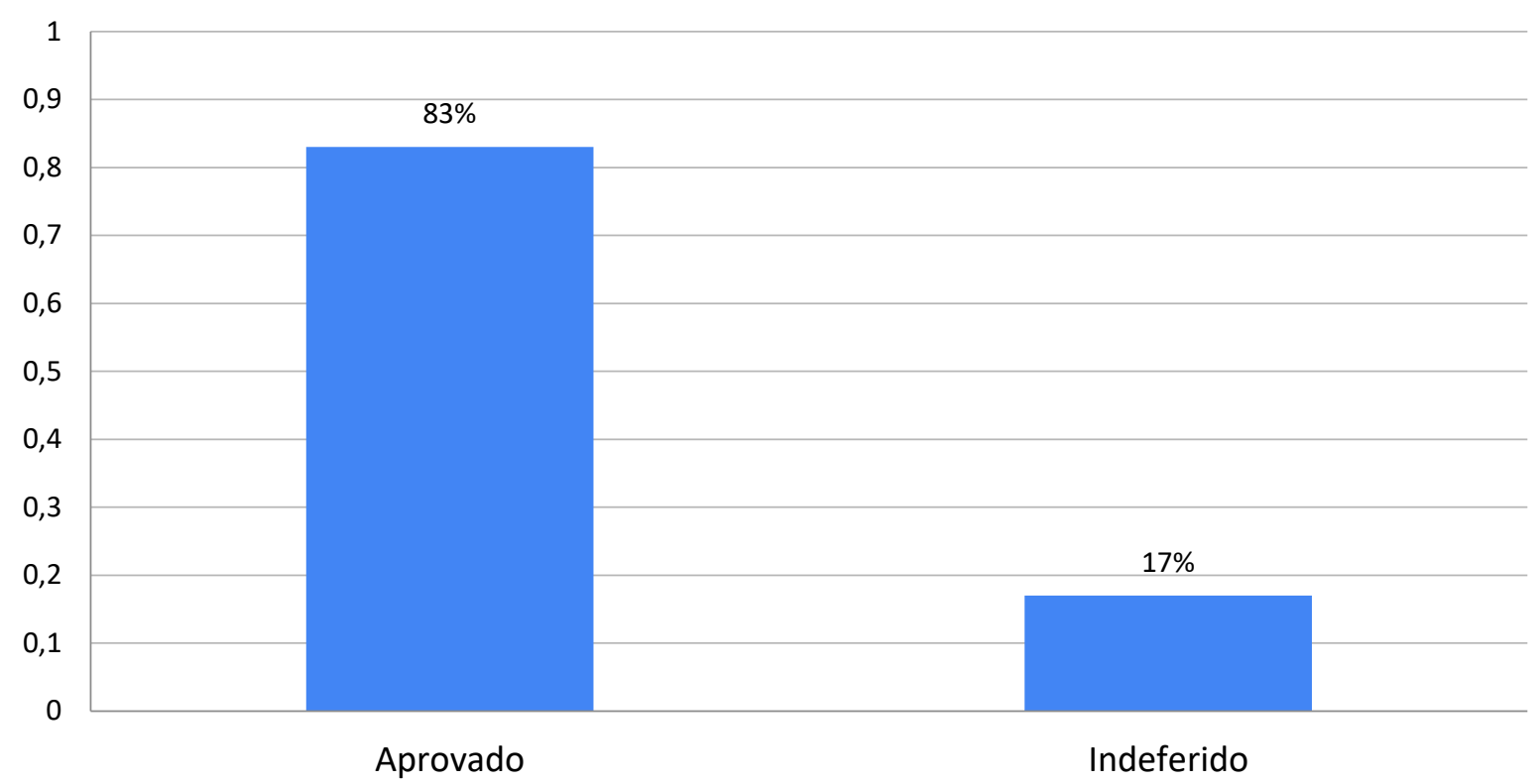

Figura 2: Dados do percentual dos candidatos considerados compatíveis e incompatíveis pela Comissão Institucional de Heteroidentificação da Univasf.

Importante salientar que $80 \%$ dos candidatos aferidos se autodeclararam pardos e apenas $20 \%$ se autodeclararam pretos. Além disso, nenhum dos candidatos autodeclarados pretos foi reprovado na primeira aferição e precisou impetrar recurso, conforme dados informados pela Comissão Institucional de Heteroidentificação.

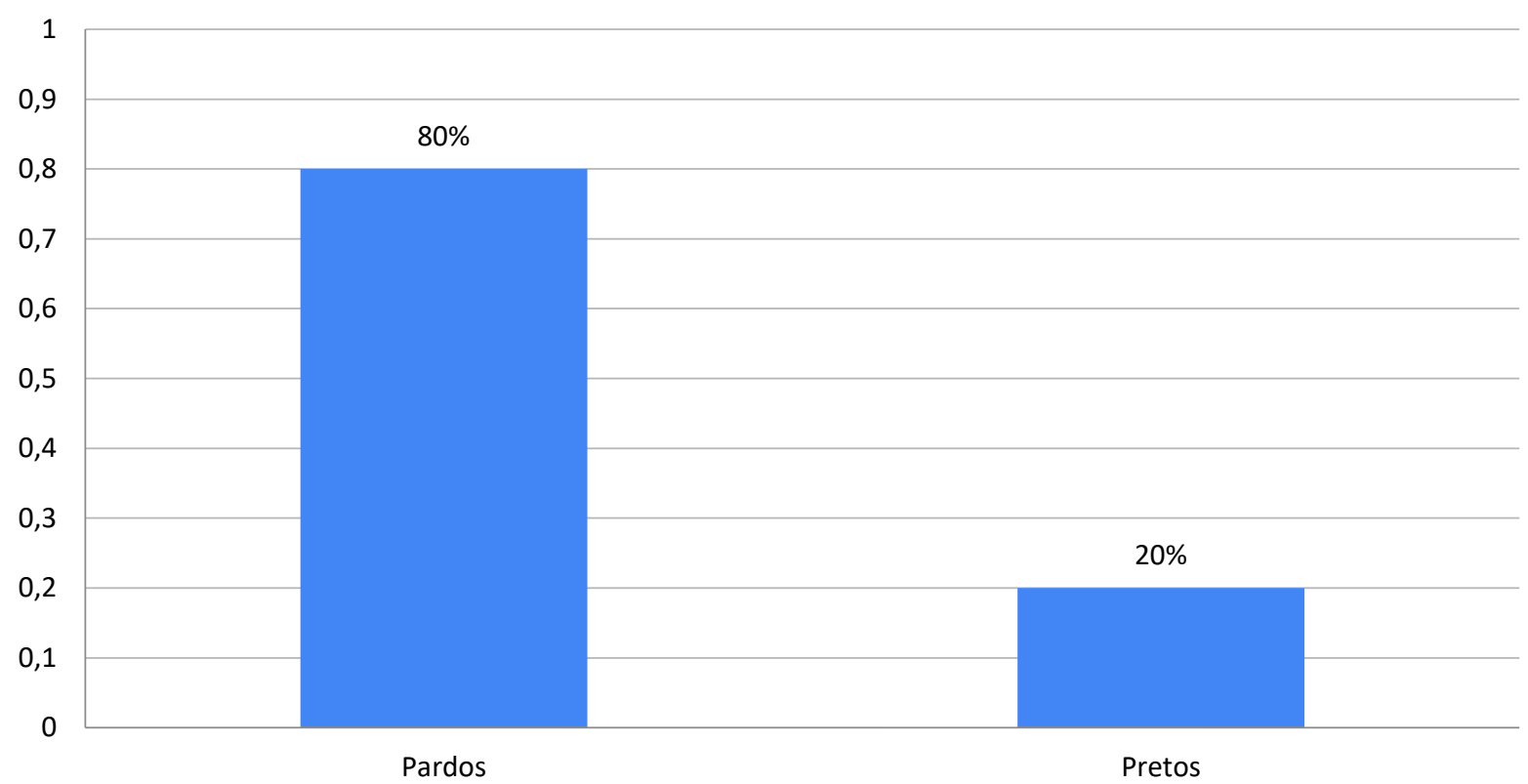

Figura 3: Percentual dos candidatos autodeclarados pardos e pretos na Chamada Regular do Sisu 2021. 
Dos números gerados pelos resultados verifica-se que a política de reserva de vagas para candidatos autodeclarados na Chamada Regular do Sisu 2021 foi implementada a contento pela Comissão Institucional de Heteroidentificação e sendo efetivamente resguardado o direito das pessoas que fazem parte da política. Ademais, é notório que a maioria dos candidatos que se submetem ao procedimento de heteroidentificação são candidatos pardos e são alguns desses candidatos também que acabam sendo reprovados. A figura do pardo implica uma certa dificuldade para a Comissão, pois devido ao processo da mestiçagem brasileira, é possível a presença da ambiguidade, tornando a tarefa um tanto árdua para definir o fenótipo do candidato, o qual é o único critério que deve ser levando em consideração nas aferições.

\section{Conclusão}

Os debates acerca das desigualdades nas condições de acesso de diferentes grupos sociais ao ensino superior estiveram presentes na pauta de organizações internacionais e movimentos populares desde o século XX (DIAS, 2017, p.131). Essas discussões deram visibilidade aos problemas de grupos historicamente discriminados, o que contribuiu para a adoção de políticas afirmativas como as cotas.

Se anteriormente as próprias Universidades elaboravam e aplicavam suas políticas de ação afirmativa de acordo com critérios próprios e necessidades identificadas de forma individual, com o advento da Lei 12.711/2012 o Estado Brasileiro passou a atuar como o grande regulador da Política de Cotas ao torná-la obrigatória, bem como por instituir um formato a ser seguido por todas as Universidades do país.

Por ser o Brasil um país marcado pela desigualdade social intimamente ligada à questão racial, a criação de instrumentos capazes de incluir a população marginalizada é fundamental para a realização da mudança social.

A Lei de Cotas definiu a técnica de autodeclaração como forma de confirmação da cor/raça do candidato. No entanto, com o intuito de reduzir o número de denúncias e evitar declarações falsas, as Universidades passaram a adotar as Comissões de Heteroidentificação que funcionam como um instituto complementar à autodeclaração do candidato. A forma de constituição das Comissões de Heteroidentificação foi estabelecida pela Portaria Normativa ${ }^{0}$ 04/2018 do Ministério do Planejamento, Orçamento e Gestão, inicialmente utilizada apenas 
para concursos públicos e posteriormente passando a ser fonte para as Universidades em seus processos seletivos de graduação e pós-graduação.

Foi nesse cenário que a Comissão Institucional de Heteroidentificação da Univasf foi criada e se encontra hoje regida pela IN 02/2021 de 12 de abril de 2021 do GR /UNIVASF. O presente artigo buscou analisar a atuação da Comissão na Chamada Regular do Sisu 2021. De acordo com os dados trazidos, restou claro que a implementação da Comissão é um fator crucial para a efetiva implementação da política de reserva de vagas, já que funciona como um instrumento para inibir fraudes e abrir os portões da Universidade para aqueles candidatos que são os reais sujeitos da política.

\section{Referências}

BRASIL. Constituição da República Federativa do Brasil de 1988. Disponível em: http://www.planalto.gov.br/ccivil 03/constituicao/constituicaocompilado.htm>. Acesso em: 14 fev. 2021.

Lei $\mathbf{n}^{\mathbf{0}}$ 12.711, de 29 de Agosto de 2012. Dispõe sobre o ingresso nas universidades federais e nas instituições federais de ensino técnico de nível médio e dá outras providências. Brasília, DF, 29 ago.2012. Disponível em: <http: www.planalto.gov.br>. Acesso em: 02 fev. 2021.

Lei $\mathbf{n}^{\circ}$ 13.409, de 28 de Dezembro de 2016. Altera a Lei $n^{\circ} 12.711$, de 29 de agosto de 2012, para dispor sobre a reserva de vagas para pessoas com deficiência nos cursos técnicos de nível médio e superior das instituições federais de ensino. Brasília, DF, 28 dez.2016. Disponível em: <http: www.planalto.gov.br>. Acesso em: 02 fev.2021.

Portaria Normativa n $\mathbf{n}^{\mathbf{0}} \mathbf{0 4}$ de 06 de abril de 2018 do Ministério do Planejamento, Orçamento e Gestão. Regulamenta o procedimento de heteroidentificação complementar à autodeclaração dos candidatos negros, para fins de preenchimento das vagas reservadas nos concursos públicos federais, nos termos da Lei n 12.990 , de 9 de junho de 2014. Brasília, DF, D.O.U, 10 abril 2018, Ed. 68, Seção 1, p.34. Disponível em https://www.in.gov.br/materia//asset_publisher/Kujrw0TZC2Mb/content/id/9714349/do1 2018-04-10-portaria-normativa-n-4-de-6-de-abril-de-2018-9714345. Acesso em: 03. Fev. 2021.

Instrução Normativa no 02 de 12 de abril de 2021 do Gabinete da Reitoria da Universidade Federal do Vale do São Francisco. Disponível em: https://portais.univasf.edu.br/normas-institucionais/normas-institucionais-1. Acesso em 20 maio 2021.

DIAS, E.M. Cotas para negros em universidades: função social do Estado contemporâneo e o princípio da proporcionalidade. Jundiaí: Paco Editorial, 2017. 
DIAS, G. R. M., TAVARES JÚNIOR, P.R.F. Heteroidentificação e cotas raciais: dúvidas, metodologias e procedimentais. Canoas: IFRS, 2018.

FAGUNDES, I.P.E. Heteroidentificação racial para concursos públicos de professores/as na Universidade Federal de Ouro Preto - UFOP. (Mestrado em Educação) - Universidade Federal de Outo Preto. Minas Gerais, p.183. 2020.

MACHADO, V. Lei de Cotas no ensino superior e racismo institucional. Jundiaí: Paco Editorial, 2021.

MUNANGA, K. Uma abordagem conceitual das noções de raça, racismo, identidade e etnia. Programa de educação sobre o negro na sociedade brasileira. Niterói: Editora UFF, 2004.

SANTOS, A. P. Itinerário das ações afirmativas no ensino superior público brasileiro: dos ecos de Durban à Lei das Cotas in Revista de Ciências Humanas, Viçosa, v. 12, n. 2, p. 289317, jul./dez. 2012.

RIOS, R.R. Pretos e Pardos nas ações afirmativas: desafios e respostas da autodeclaração e da heteroidentificação in Heteroidentificação e Cotas Raciais: dúvidas, metodologias e procedimentos, Canoas, RS: IFRS campus Canoas, 2018.

Como citar este artigo (Formato ABNT):

SILVA, Leilane Diena Souza da; SANTOS, Marcelo Henrique Pereira dos. A Atuação da Comissão Institucional de Heteroidentificação da UNIVASF na Chamada Regular do SISU 2021 para Cursos de Graduação Presenciais. Id on Line Rev.Mult. Psic., Julho/2021, vol.15, n.56, p. 495-511, ISSN: 19811179.

Recebido: 25/05/2021;

Aceito: 03/07/2021. 